\title{
Children as carers
}

\author{
Jo Aldridge, Saul Becker
}

There is a considerable research literature which focuses on the lives and needs of informal carers in the community. ${ }^{1}$ Some of this literature examines the impact of the caring role on the physical and mental health of carers. $^{2}$ However, the literature fails to examine in any depth the particular experiences and needs of children who care. In effect, child carers have been excluded from the wider policy debate on informal and community care. Nowhere in the guidelines to the NHS and Community Care Act (finally implemented on 1 April 1993) are child carers specifically mentioned, despite the principle of the act which is based on listening to carers generally and providing for their needs.

A recent General Household Survey indicates that there are about 6.8 million people in Great Britain who are looking after a sick, disabled, or elderly person. ${ }^{3}$ It is impossible to derive from these data any figures on the proportion of carers who are children. Neither are there any other data sets which could provide us with this information. A new study, conducted by the authors, however, shows that children under the age of 18 who are providing primary care for a sick or disabled parent or relative in the home run considerable risks to their physical and psychosocial well being. ${ }^{4}$ The findings of the research form the basis of this paper. The research challenges the received wisdom that carers are a homogeneous group. It suggests that the age of carers is of critical importance - in particular the age when caring commenced - in terms of the influence on lifestyles, needs, opportunities, and health.

\section{The literature on young carers}

It has been documented that there is a dearth of literature on young carers ${ }^{5}$ - what one might term 'a literature of omission'. Certain small scale studies have attempted to determine or assess the possible numbers of children involved in caring nationwide. ${ }^{67}$ These have suggested that nationally there may be 10000 children who act as primary carers, although of course there will be many more who share the care with others. However, methodological issues associated with these figures suggest they are unreliable. To date, no one knows how many children act as primary carers in the UK. Little attention has been paid to their needs as children and as carers. Indeed young carers are mostly presented as an adjunct to a different, adult subject group.
The work of the Carers National Association Young Carers Project (CNAYCP), funded by the Department of Health, has been influential in awareness raising and enabling and empowering some young carers in the community. Their studies endorse a child centred view and examine the social impact of caring in terms of the quality of life of young carers. ${ }^{8-12}$ Meredith, the first project worker at the CNAYCP, has suggested that young carers are the 'unacceptable face of community care'. ${ }^{11}$ They are expected to provide care with little support and at great personal cost. The CNAYCP emphasises the need to undertake quality of life or investigative studies and to avoid further repetition of statistically based research (which in the past has been rather crude in terms of method and analysis).

There is a body of literature relating to specific conditions and disabilities that adopts the care receiver's perspective, or focuses on the care receiver's disorder, but which incorporates children as carers because of the nature of the particular medical condition. ${ }^{13-15}$ Such work is most apposite in addressing the experiences and needs of the child as carer and the child at risk (both from the effects of early caring and the risks of disease).

Because of the severity of certain disorders and their physiological effects on adults, the impact on the family as a unit - and therefore the child(ren) - is considerable. For example, where Parkinson's disease affects a parent in the family environment, it has a subsequent impact on the child(ren). ${ }^{13}$ Where Huntington's chorea is present the consequences in terms of the effects on the child(ren) are considerably more complex. ${ }^{1415}$ In these cases, the nature of the disease enforces action on the part of both medical and welfare professionals. It inevitably imposes a child centred view.

In the case of Huntington's chorea 'perhaps the most serious disorder of adult life that faces the medical geneticist ${ }^{15}$ - there is serious concern for the child, not only because of the indirect effects of having to care for a parent with the disease, but also the direct effects of the hereditary nature of the condition. As well as the recognition of the impact of transmission of Huntington's chorea, there is also consideration of the role the child undertakes as carer. Tyler for example highlights the effects of Huntington's chorea and how it can compromise the parental role, resulting in stressful home conditions and an extra burden of responsibility on 
the child. ${ }^{15}$ Thus it is important to recognise that the nature and severity of the adult's illness or disability is not only a determining factor in the emotional or physical effects on the child, but also on the level of responsibilities (that is caring) the child must undertake.

In terms of the provision of information, Honigsbaum's work on HIV, AIDS, and children is particularly relevant. ${ }^{16}$ Honigsbaum recognises the key needs of children - being heard, being included in discussions, and being given access to information - all of which are directly relevant to children who are involved in the caring process.

\section{The effects of caring on children}

The effects of caring on a child can be manifold and complex. This is certainly the case where the nature and extent of caring responsibilities are intense - in those circumstances where the child carer is the sole provider of care; where there are no other adults in the home aside from the care receiver; and where the care receiver's condition is such that it requires constant attention.

Caring can severely restrict children's lives. It can have implications for their physical and psychosocial development as well as their educational prospects. In cases where the care receiver's mobility is impaired, often children are forced to lift their parent(s). In many cases, this can cause injury or exacerbate current strains. Lifting is a technique which requires carefully applied training and yet children are not usually the recipients of training in this area. Clearly professionals who might be able to respond to such needs are not necessarily willing to train children because of the implications of condoning the lifting of adults by children.

Friendships and social activities are also severely impaired when children undertake primary caring roles. The extent of their duties can mean they often have to forgo socialising, and friendships can suffer as a result (other children who do not have to care may not understand the nature and extent of the caring experience). Caring can also place a 'silent curfew' on children (self imposed or imposed by others), so that when they do go out, they often have to return early to carry out their duties, or the care receiver can put pressure on children to return early to the family home. Clearly if all these factors combine, then considerable pressure is placed on children, which can often result in them restricting their social activities and friendships, sometimes completely, and focusing their attention entirely on the family (caring) environment.

It is a fundamental right of all children to have access to education, but many young carers are denied this right because of their caring duties. Persistent lateness and absences (sometimes long term) are often symptoms of caring. However, it is often problematic for school staff to identify children who are caring because of their reluctance to tell. But it is the responsibility of teaching and school staff to recognise stresses or strains in children, especially when they result in frequent absences. Children may be reluctant to talk about their home conditions, but they must be encouraged to do so by professionals who can talk to children sensitively and with understanding.

\section{Identification or punishment}

Perhaps the relative lack of research focusing specifically on young carers and their needs is indicative of the fact that children who care remain hidden in the community, often through their fear of coming to the attention of paid professionals who might threaten the pattern and fabric of their home life, such as it is.

Although many key medical, health, and social care professionals may be involved in families where there is long term adult illness or disability, they are not necessarily identifying primary carers when these carers are children. It has been suggested that a traditional intervention from social services and education welfare officers is to prosecute and to put children into care where the child's welfare, education, and development is threatened. ${ }^{4}$ As a consequence children who care may become willing participants in their own silence, in order to avoid separation from their families. Many children also associate reception into care with punishment and control (being put into care with juvenile offenders). To be punished for caring is hard to comprehend when you are a child carer. And the messages that this gives children during a critical stage of their psychosocial development may influence the way they perceive, and value, caring and family responsibility in adult life.

Professionals such as general practitioners, community care assistants, nurses, social workers, and education welfare officers must begin to recognise children who are providing primary care for their parent(s) in the home. But they must also approach the issue, and child carers, with sensitivity, lest they provoke fear on the part of children, who can make themselves even more invisible if they anticipate punishment and separation from loved ones.

\section{Early socialisation}

Children can be socialised into the caring role from an early age. Often there is no alternative but for a child to provide care - especially in one parent families or where both parents are ill or disabled. To punish these children and their families therefore seems even more perverse.

Children may adapt to the role, they may even derive a sense of wellbeing or self worth from the provision of care for their parent, but their sense of worth and identity is compromised and confused when they experience professional interventions which they associate with control and correction. Certainly questions must be asked about whether it is right that children should be 
having to adapt to and provide such roles. Much evidence and work has focused on the rights and needs of children (the 1969 Family Reform Act, the 1989 UN Convention on the Rights of the Child, the 1989 Children Act) which includes the right to physical and mental well being, to a secure home life, education, play, recreation, etc. When children are caring many, if not all of these rights are undermined. There is no promotion of security in the caring role, quite the contrary. Furthermore, it is important to consider the effects on children of having to carry out personal and intimate tasks for their own parents - becoming in effect, their own parents' parent.

A World Health Organisation study suggested that children need to be able to gradually extend their responsibilities in the family environment. ${ }^{17}$ However, often young carers' responsibilities have a sudden onset and can begin at a very early age. Furthermore, caring responsibilities can often coincide with the death or sudden absence of the other parent, so the child has sole responsibility for the care of the remaining parent. This naturally has implications for the loss of childhood ${ }^{18}$ often children have to grow up very fast if they are to adapt to the responsibilities usually pertaining to adulthood - preparing meals, cleaning, performing personal, intimate tasks for their parent(s).

Indeed there are many emotional aspects surrounding the issue of children who care. It is important to consider issues of dignity and embarrassment when children are having to, for example, shower, dress, or toilet their parents. Such duties are humiliating and degrading for both children as carers and their parent(s) as the recipients of their care. The long term psychological impact of, for example, wiping their parents when they lose control of their bodily functions due to their illness, have yet to be fully explored. If we pursue these issues, then others, perhaps even of a more fundamental nature, arise. For example, what level of responsibilities should children have in family life? Is it appropriate for children to be accountable for the care of their parents? These are critical considerations. The evidence indicates that many children who care take on primary responsibility and accountability for their parents' care; that as a consequence the 'traditional' expectations, roles and relationships between adult and child are largely turned upside down; that the effects on children's lives both inside and outside the home are profound. The dividing line between what is acceptable and not acceptable in family life is often a very thin one. Young carers are very much on the boundaries of that line.

\section{Ways forward}

It has been suggested that the provision of services can reduce the levels of stress on carers, ${ }^{1}$ but presently there are no methods of reducing the strain on young carers as there are no services currently targeted at their needs.

In considering provision for young carers it is important that adults do not impose their own ideals concerning their best interests. Nor should it be assumed that models of service delivery which apply to adult carers, or groups of other people in need, would work equally well for young carers.

Guidelines or approaches for action should be based upon the child carer's own statements of need. Indeed, the starting point when considering the way forward is to acknowledge the unique situation of each young carer, so that any assessment of their needs is made on an individual basis. What is right for one young carer might not be right for another.

Any guidelines for the provision of young carers' needs or service delivery must inevitably be based on philosophical and pragmatic principles. These include the recognition and observation of children's rights, practical policy recommendations based upon these rights and pragmatic considerations in relation to professional intervention and service arrangements. Alderson has suggested that 're-thinking childhood in terms of rights opens the way for children to be consulted more fully in defining their interests'. ${ }^{19}$

Young carers also need information, ${ }^{4}$ and one immediate and very real help to them would be the provision of resources and information which would give them the opportunity to better express their own needs in terms of services and also to provide them, and their families, with information - on advice and counselling agencies, benefits, medical information or 'helplines' - which is crucial to the quality of their day to day lives.

Finally, service planners and providers need to be more aware, better trained, sensitive, and proactive - rather than just responding to crises as they arise. But it is also essential that interagency and interprofessional communication is improved. Young carers have often fallen into the gaps between social services and education, and between health and social care. Agencies need to work together for children who care to promote their welfare and development, rather than against them by threatening to punish them for being carers.

We are indebted to the multidisciplinary steering group who supported our research in Nottingham, and to Nottingham Health Authority Joint Finance who funded our initial study of children who care. We also acknowledge the work of the Nottinghamshire Association of Voluntary Organisations, which coordinated the research.

1 Twigg J, Atkin K, Perring C. Carers and services: a review of research. Social Policy Research Unit. London: HMSO, 1990.

2 Glendinning C. The costs of informal care: looking inside the household. Social Policy Research Unit. London: HMSO, 1992.

3 Office of Population Censuses and Surveys. General household survey: carers in 1990. (OPCS monitor SS 92/2.) London: HMSO, 1992

4 Aldridge J, Becker S. Children who care: inside the world of young carers. Loughborough: Department of Social young carers. Loughborough: Departme

5 Fallon K. An involuntary workforce. Community Care 1990;

6 O'Neill A. Young carers: the Tameside research. Manchester: Tameside Metropolitan Borough Council, 1988.

7 Page R. Report on the initial survey investigating the number of young carers in Sandwell secondary schools. West Midlands: Sandwell Metropolitan Borough Council, 1988.

8 Meredith H. A new awareness. Community Care 1990; 22 Feb: 6

9 Meredith $\mathrm{H}$. Developing support for young carers. The Carer 1991; Jan: 9. 
10 Meredith H. Young carers. Contact 1991; Summer: 14-5.

11 Meredith $H$. Young carers: the unacceptable face of community care. Social Work and Social Sciences Review 1991; 3 (suppl): 47-51.

12 Meredith $\mathrm{H}$. Supporting the young carer. Community Outlook. 1992; May: 15-7.

13 Grimshaw R. Children of parents with Parkinson's disease. A research report for the Parkinson's Disease Society. research report for the Parkinson's Disease Society.

14 Harper $P$. The prevention of Huntington's chorea: the Milroy lecture 1985. F R Coll Physicians Lond 1986; 20: $7-14$
15 Tyler A. Helping the children to cope. Combat Newsletter 990; Spring: 1-5.

16 Honigsbaum N. HIV, AIDS and children: a cause for concern. London: National Children's Bureau, 1991.

17 World Health Organisation. Manuals on child mental health and psychosocial development. Geneva: WHO, 1982.

18 Bilsborrow S. You grow up fast as well ... Young carers on Merseyside. Merseyside. London: Carers Procial Services Society, and Barnardos, 1992 19 Ald P. Rights of children and young people. In: Coot A, ed. The welfare of citizens. London: Rivers Ofram Press, 1992: 153-80. 